\section{Ética y medicina en Michel Foucault: La dimensión humanística de la medicina a partir de una genealogía de la moral}

Ethics and medicine in Michel Foucault: The humanistic dimension of medicine derived from a genealogy of morality

Benjamim Gomes

Faculdade de Ciências Médicas y Faculdade de Enfermagem Universidade de Pernambuco FCM/FENSG/UPE

Av. Boa Viagem 4.70, ap. 1.204 51.021-000 - Recife - PE - Brasil benjamimgomes@hotmail.com
GOMES, B.: Ética y medicina en Michel Foucault: La dimensión humanística de la medicina a partir de una genealogía de la moral.

História, Ciências, Saúde - Manguinhos, v. 12, n. 3, p. 717-34, set.-dez. 2005.

Este trabajo presenta una tesis doctoral leída en la Universidad de Salamanca y basada en los escritos de la última década de Foucault. Si escribiendo la Historia de la sexualidad su objetivo fue hacer una genealogía de la ética, analizándola, junto con los demás escritos suyos, mi objetivo es enseñar su última aportación a la historia de la medicina. El parte de una concepción de poder sobre los demás hacia una concepción de poder sobre uno mismo, espacio exclusivo de la antigua moral griega. Como pensador que busca comprender los problemas de hoy yendo a sus raíces, más que historia Foucault hace filosofía de la historia. Considerado un antihumanista, él nos deja el retrato de una medicina absolutamente ético-humanística.

PALABRAS-CLAVE: historia de la medicina; ética deontológica; dimensión ontológica; medicina ético-humanística.

GOMES, B. Ethics and medicine in Michel Foucault: The humanistic dimension of medicine derived from a genealogy of morality.

História, Ciências, Saúde - Manguinhos, v. 12, n. 3, p. 717-34, Sept.-Dec. 2005.

The article presents the results of a doctoral dissertation defended at the Universidad de Salamanca, based on Foucault's final decade of writings. If Foucault's goal in writing The History of Sexuality was to fashion a genealogy of ethics, my goal in analyzing this book, along with his other writings, is to demonstrate his last contribution to the history of medicine. He moves from a conception of power over others towards a conception of power over oneself, an exclusive terrain of ancient Greek morality. As a thinker who tries to understand today's problems by going to their roots, Foucault develops less a history than a philosophy of history. Considered an anti-humanist, he leaves us with a portrait of a wholly ethical-humanistic medicine.

KEYWORDS: history of medicine; deontological ethics; ontological dimension; ethical-humanistic medicine. 


\section{Introducción}

T a investigación aquí presentada resulta de una tesis doctoral L leída en la Universidad de Salamanca en 2003 y tiene como referencia primera los escritos de Michel Foucault publicados en la última década de su vida, destacándose, entre ellos, L'usage des plaisirs y Le souci de soi, conocidos como los volúmenes dos y tres de su Historia de la sexualidad. En un parangón con el primero, La volonté de savoir, publicado en 1976, puede verse que estos dos últimos libros rompen el hilo conductor que tendría que haber entre volúmenes de una misma obra. En un largo apartado llamado 'Introducción' que inicia el volumen II de esta obra, el filósofo explica el giro que le ha dado a su Historia de la sexualidad después de escrito el volumen I; parte de una concepción de poder sobre los demás hacia una concepción de poder sobre uno mismo, espacio exclusivo de la antigua moral de los griegos y grecorromanos.

Considerando en la obra del filósofo la importancia de éste y de otros giros suyos, el primer capítulo de la tesis, 'El giro de Michel Foucault', es un texto panorámico porque tiene como objeto la totalidad de sus escritos. Para mí, la importancia de este capítulo es situarme y situar a los lectores de mi tesis en la extensa y, para muchos, heterogénea obra de Foucault, pues se trata de un pensador cuya producción tiene una temática muy diversificada; él ha escrito sobre cuestiones muy distintas y casi nunca constitutivas del pensamiento filosófico. Por último, escribe esta supuesta Historia de la sexualidad, donde no hace historia, sino una genealogía de nuestra ética sexual moderna. Aunque el título de algunos de sus libros sugiere que se trata de la obra de un historiador, él no lo es, no hace historia, tampoco es un moralista, sino un pensador contemporáneo que busca comprender los problemas de la actualidad yendo a sus fuentes y a sus raíces para comprenderlos en el contexto de su provisionalidad.

Teniendo como trasfondo esta su llamada Historia de la sexualidad, analizo el discurso ético del pensador francés, como lo hace él, apoyado en filósofos y médicos de la Antigüedad clásica y grecorromana que va del siglo IV a.C. hasta Galeno, en las postrimerías del siglo II de nuestra era o inicio del III. Si escribiendo su Historia de la sexualidad el objetivo de Michel Foucault es hacer una genealogía de la ética, analizándola y a los demás escritos de su última década, mi objetivo es enseñar su aportación a la historia de la medicina. Considerando este objetivo, claro que la referencia mayor de mi análisis, más que los filósofos, es el pensamiento ético de los médicos de entonces.

Aunque pueda decirse que en su Historia de la sexualidad no hay un puente con la actualidad y que los demás escritos de esta época nada tienen que ver con la medicina, el análisis que presento deja 
${ }^{1}$ En L'usage des plaisirs, 1984, p. 16-9, Foucault trata de estas cuestiones enfatizando la dimensión filosófica, por lo tanto ética y estética de su análisis. También en las primeras páginas de la entrevista 'A propos de la génealogie de l'éthique: un aperçu du travail en cours' con Hebert Dreyfus y Paul Rabinow, en 1982, con cambios del filósofo para su publicación en francés en 1984, Foucault insiste en el carácter estético de la moral antigua y que su historia de la sexualidad no es historia, sino una genealogía de la ética. En sus dos versiones esta entrevista está republicada en Dits et écrits II, 2001b, respectivamente, $\mathrm{p}$ $1202-30$ y p. $1428-50$ muy clara la vigencia de estos escritos y que los historiadores contemporáneos de la medicina no han dado la debida importancia a una cuestión que es muy relevante en el contexto de la medicina actual: la ética médica del período analizado es una referencia crítica indispensable para una discusión y reelaboración de la ética médica contemporánea. Ésta se presenta hoy caracterizadamente como una ética deontológica, centrada en el código; la ética médica de los antiguos, retratada por Foucault y objeto de este análisis, es una ética ontológica, centrada en el hombre como sujeto moral de sus propias acciones. No es un código que da el norte de la conducta moral de los antiguos, sino una preocupación ética centrada en uno mismo y en criterios 'de orden estética', por ello conocida como una ética que es también 'arte de la existencia' o una 'estética de la existencia'. ${ }^{1}$

Si los pequeños escritos del filósofo, constituidos sobre todo de artículos, conferencias y entrevistas, no hacen referencia a la práctica de la medicina de entonces, son todavía indispensables a la comprensión de una antigua ética médica cuya dimensión es ontológica. La filosofía que se expresa en estos textos no puede ser reducida a una forma de conocimiento porque, de hecho, es una actitud y "una forma de vida" (Hadot, 1998; 1995) que conlleva una ética necesariamente ontológica. Desde el Juramento de Hipócrates, el testimonio ético de los médicos, referidos por Foucault, nos enseña que su ética no significa la adhesión a un código, sino el cumplimiento de un compromiso del médico con uno mismo, con su conciencia y convicciones personales y ahí está una expresión de la dimensión ontológica de la ética médica.

Veremos como esta investigación intenta responder al contexto contemporáneo de una medicina aún positivista y muy tecnicista cuya preocupación es sólo la cura de la enfermedad del paciente, concebido como ser fragmentado, y nunca el bienestar del hombre, tomado en su totalidad psicosomática. Partiendo de este reto, la investigación llevada a cabo no es sólo un trabajo académico y formal; se inserta en una historia de luchas y peleas cuyo fin es la humanización de la medicina contemporánea. La necesidad de profundización y teorización para implantar y conducir las reformas curriculares de la carrera médica, hoy una prioridad nacional, hace que esta investigación pueda ser una contribución como instrumento teórico de embasamiento. En estas circunstancias, esta investigación puede tener eco en todo su entorno académico e institucional, local y extramuros.

\section{¿Por qué Michel Foucault?}

Como una presentación teórico-académica, hay que decir ¿por qué en esta investigación la opción se ha centrado en Foucault? Si 
tantos médicos tienen en sus escritos una preocupación humanística, ¿por qué elegir a Michel Foucault como referencia primera de esta investigación? ¿Qué importancia tiene su discurso como filósofo para considerarlo un pensador que ha dejado una contribución significativa en el área de la medicina? Para adentrarme de veras en las cuestiones profundizadas en esta investigación, hay que dilucidarlas. Desde el comienzo de mi último encargo - la enseñanza a los alumnos de enfermería y medicina - necesitaba yo del soporte filosófico que facilitara contestar a los desafíos ético-humanísticos que me proponía la práctica docente. Consideraba que una alternativa podría ser partir de un pensador cuyo discurso pudiera enseñarme cómo hacer la filosofía convertirse en una referencia a la práctica de la medicina o de la enfermería contemporáneas.

En cuanto a Foucault, cabe observar que desde los inicios de su carrera, sobre todo en los años 60, a él le han interesado cuestiones que tienen que ver con la psiquiatría, el psicoanálisis y la medicina clínica (Foucault, 1954; 1961; 1963). Si estos términos no se constituyeron en una investigación aislada y si estas cuestiones no tienen su sistematización en un libro, fueron sin embargo cuestiones presentes en todo el recorrido del filósofo. En la lectura primera que hice de este autor me llamó la atención el pensamiento ético de los médicos antiguos como una referencia importante para los médicos contemporáneos (Foucault, 1984a; 1984b). Sin duda, ésta fue una de las muchas cuestiones que me han sugerido un análisis riguroso, por lo tanto de carácter filosófico, acerca del pensamiento ético de los médicos griegos, considerando su mensaje y su recado a los médicos de la actualidad.

Si se trata de un análisis riguroso, es porque la crítica y el rigor son metodológicamente constitutivos del trabajo filosófico. No hay filosofía si no es crítica y rigurosa y los escritos de Foucault, además de otras, tienen esta característica; la criticidad es un carácter explícito de su discurso. Hay más, aunque haya quien lo denomine un historiador o un pionero del análisis del discurso, prefiero considerarlo un filósofo porque, de forma crítica y rigurosa, él va adonde hay un problema y lo analiza. La filosofía no tiene un objeto propio sino que abarca cualquiera que sea el problema, esté donde esté. De esta forma, la 'totalidad' es también característica del discurso foucaultiano. Vale observar que este término es polémico; en Aristóteles, Kant o Marx su significado no es lo mismo. Aquí 'totalidad' es utilizado para referirse a la gran amplitud de los problemas de investigación filosófica. Hay que decir aún que él trata de las cuestiones de las que se preocupa yendo a sus raíces, por ello puede considerarse la radicalidad como otra característica de su pensamiento.

Si para Dermeval Saviani son características de la filosofía la totalidad, la radicalidad y la crítica rigurosa (1980, p. 24-7), leyendo 
2 Aún en la entrevista referida anteriormente (p. 1430), el filósofo hace referencia a un libro suyo sobre moral sexual en el siglo XVI y a Les aveux de la chair, libros nunca publicados; él también dice que L'usage des plaisirs fue escrito tres veces (p. 1429). La referencia al cambio que es para él el acto de escribir un libro es de una entrevista de final de 1978 con Trombadori, 'Entretien avec Michel Foucault' (DE II, 2001b, p. 861). a Foucault me parece válido añadir la provisionalidad como una cuarta característica del acto de filosofar. En todos sus escritos él huye de referirse a lo que ha dicho anteriormente. Varias veces, tras escribir un libro no lo ha publicado porque ya piensa de otro modo; L'usage des plaisirs, por ejemplo, fue publicado después de escribirlo por tercera vez. La referencia que hace al cambio personal que significa el acto de escribir un libro nos enseña lo provisional de su pensamiento; él dice en una entrevista suya: "Cada libro transforma lo que yo pensaba al terminar el libro escrito anteriormente"; él añade un poco más y dice: "yo escribo para cambiarme a mí mismo y no más pensar la misma cosa que antes". ${ }^{2}$

Considerados bajo el enfoque antes explicitado, estos cuatro términos, totalidad, radicalidad, criticidad y provisionalidad, propios del acto de filosofar, son características de los escritos del pensador francés. Pese a las opiniones divergentes, para mí es tranquilo considerarlo filósofo en toda su producción, aun cuando se presenta con un ropaje de carácter literario o histórico, a ejemplo de sus escritos de los años 60 o de su supuesta Historia de la sexualidad. De hecho, en todo su recorrido Foucault no hace historia sino filosofía de la historia.

La lectura que hago de los últimos escritos de este pensador me lleva a verlos como una genealogía de la ética, como él propio afirma en una entrevista con Hebert Dreyfus y Paul Rabinow (Foucault, 2001b, p. 1437); esa lectura me hace ver también una teoría ética en esta genealogía. Como teoría tiene una doble función. La teoría ética foucaultiana, primero, se presenta como portadora de una posibilidad de utilización ad intra o mejor, 'hacia dentro'; ella respalda su propio discurso. Foucault elabora su propia teoría a partir de la cual desarrolla su investigación. La indicación 'hacia dentro' de esta teoría permite que se pueda verificar su coherencia interna; si la problematización que da origen a su investigación es aclarada al final. Hay que analizar la teoría ética de este autor con vistas a su utilización como soporte teórico de la genealogía que escribe; su teoría ética respalda esta genealogía y permite comprender la ética médica de entonces.

La doble función de una teoría permite decir que la teoría ética de Foucault no sólo respalda sus investigaciones; traspasa también la amplitud del pensamiento foucaultiano cuando sirve de soporte de análisis a cuestiones puestas por otro investigador. Hoy, la vigencia de esta teoría es expresión de su relevancia ad extra o 'hacia fuera'; ella vale como una referencia teórica para un análisis riguroso y crítico de otras cuestiones levantadas por quien lo quiera hacer. La lectura que he hecho de sus escritos me lleva a considerarlos una teoría portadora de los mecanismos teóricometodológicos suficientes a las exigencias de respaldar otros análisis. Por ello utilizo esta teoría como referencia primera de investigación, 
aunque haya que acudir a otras como referencia complementaria. Claro que los escritos de Foucault y sus fuentes no son exclusivos para llegar a las conclusiones a las que he llegado.

Arriba decía que necesitaba de un soporte filosófico mayor y de un pensador cuya obra fuese una referencia teórica y crítica a la medicina contemporánea. De hecho, el planteamiento aquí desarrollado demuestra que gran parte de los escritos foucaultianos son referencias que se imponen a aquéllos que se interesan por la historia de la medicina y por la crítica a la psiquiatría y al psicoanálisis. A la postre, sus últimos escritos son relevantes para analizar la dimensión ético-humanística de la medicina contemporánea. Más específicamente, considero que la ética médica de los antiguos expresada en los escritos del filósofo es una referencia muy importante para el análisis, la discusión y la reelaboración de la ética médica contemporánea.

Me parece discutible acusar a Foucault de no establecer un puente con la modernidad cuando escribe su Historia de la sexualidad. Al hacer una genealogía de la ética, el filósofo retrata la preocupación ético-humanística de los médicos de la Antigüedad. La forma como lo ha hecho nos deja como herencia una teoría que permite que se pueda analizar el pasado de la medicina en una perspectiva crítica y el presente de esta medicina en la perspectiva de cambios significativos. Puede inferirse de la lectura de los últimos libros de Foucault que, si él no hace el puente con el presente cabe hacerlo a los que a partir de su obra lo toman como referencia de análisis o de una investigación. La teoría ética foucaultiana permite a quien lo desee hacer este puente con la contemporaneidad: ése fue uno de los propósitos del presente estudio.

\section{Problematización y desarrollo}

La investigación llevada a cabo fue un intento de contestar muchas de las cuestiones que me proponía en mi recorrido de docencia, desde que me hice cargo de las asignaturas de Filosofía de la Ciencia, Ética o Bioética, impartidas a los alumnos de las carreras de medicina y enfermería en la Universidad de Pernambuco. Entre tantas cuestiones, algunas deben ser explicitadas en el contexto de la problematización a la cual pretende responder la investigación realizada.

Siendo filósofo, me molestaba el desafío que era para mí asegurar la motivación de los alumnos cuyo interés está dirigido casi con exclusividad hacia las asignaturas denominadas científicas, como la anatomía, la biofísica, la bioquímica. Es una pena que muchos sean estimulados a pensar "el proceso salud-enfermedad en términos estrictamente biológicos o mecanicistas, sobrevalorando el rol de los recursos diagnóstico-terapéuticos" (Barros, 2002). No sólo entre 
alumnos, también entre docentes de esas y otras asignaturas específicas de medicina y carreras afines, no es corriente la valoración de contenidos humanísticos en sus currículos; para ésos el discurso sobre una medicina ética y humanística es considerado una cuestión de muy poco interés.

De hecho, el problema-clave que está en el origen de esta investigación se expresa concretamente en el divorcio existente, desde comienzos de la modernidad, entre medicina y filosofía o entre tecnicismo pragmatista y la práctica de una medicina humanística. Este divorcio conlleva la pérdida de una concepción de hombre que ya no es holística; esta pérdida aparece mediante una visión fragmentaria del cuerpo, fruto de los avances técnico-científicos, que genera las especialidades sobrevaloradas en el seno de la medicina, con absoluto descuido de contenidos ético-humanísticos.

En la gran mayoría de las escuelas médicas el currículo tiene sólo las asignaturas específicas de esta carrera, aunque haya asignaturas aisladas cuya nomenclatura pueda sugerir contenidos de carácter humanístico. Hasta hace muy poco tiempo, la ética médica se reducía a una dimensión meramente normativa y jurídica, y se confundía con las asignaturas del currículo tradicional llamadas deontología y medicina legal. Hoy, se extiende la conciencia de que la dimensión normativa o jurídica no basta para contestar los retos de una época en que se logra un poder técnico y científico casi infinito; en este nuevo contexto "la ética tiene algo que decir en las cuestiones relacionadas con la técnica". Para Hans Jonas "que la técnica está sometida a consideraciones éticas se desprende del sencillo hecho de que la técnica es un ejercicio del poder humano y una forma de actuación, y como actuación humana está expuesta a su examen moral" (Jonas, 1997, p. 33).

Si en un pasado más reciente algunas facultades de medicina, como la Facultad de Ciencias Médicas en Nordeste de Brasil y otras escuelas médicas del sur, tuvieron la iniciativa de introducir en sus currículos asignaturas de carácter humanista (filosofía de la ciencia, sociología de la salud, antropología médica o historia de la medicina), esto sólo representó intentos aislados cuyo blanco fue contestar a las inquietudes, discusiones y polémicas que resultaban del divorcio existente entre tecnicismo pragmatista y humanismo médico. Como puede verse, estas iniciativas se deben a un grupo pequeño de docentes, pero pionero y muy actuante, comprometido con los cambios que resultan de estas contradicciones y que tienen como fin la humanización de la medicina.

Actualmente, se extiende cada vez más la crítica al teoricismo y tecnicismo pragmatista de la medicina; sin embargo esto no impide la ambigüedad docente, y muchas resistencias de carácter teóricometodológico en la gestión de los contenidos ético-humanistas que deben hacer parte de la enseñanza médica. No se cuenta en su 
totalidad con la adhesión docente hacia la articulación entre teoría y práctica o hacia la interrelación entre un tecnicismo pragmatista y la dimensión ético-humanista de la medicina. No parecen claros los límites y la distinción entre conceptos como práctica y pragmatismo y de ahí viene el riesgo de un currículo caracterizadamente pragmatista; también no es clara la distinción teórica entre la dimensión filosófica y el carácter ideológico de determinados contenidos. Esto compromete mucho la reelaboración de contenidos del currículo que, además de la competencia tecnocientífica, no debe olvidar la formación de una conciencia moral y crítica.

Desde el principio hay que decir que la problematización que ha dado origen a esta investigación puede ser aclarada de forma sucinta con una expresión muy optimista: "Del tecnicismo pragmatista hacia una medicina ético-humanística"; éste es mi problema de investigación y también mi reto docente en la Universidad de Pernambuco. La aclaración de este problema es imprescindible para que se pueda evaluar su importancia académica como respuesta a los desafíos ya identificados en este texto. Hay que precisar muy bien el problema de investigación. Helo aquí: la ciencia y la tecnología han traído muchos avances a la medicina; no obstante también han engendrado desafíos éticos cada vez más graves, entre los cuales cabe señalar el permanente agravamiento de las condiciones de salud y de existencia de una mayoría excluida de aquellos avances, los riesgos para la vida y una efectiva agresión a los supremos valores éticos.

Frente a esta problematización, hay que reconocer la ambivalencia del conocimiento científico y de la tecnología de punta con consecuencias, incluso, cada vez más mortíferas. Hay que posicionarse de forma crítica frente a estos avances científicos y esto basado en los valores éticos derivados de la dignidad del hombre. Además de la formación científica, hay que buscar la formación de una conciencia moral y crítica. Esto no resulta de conocimientos de carácter cognitivo ni del avance de la ciencia médica, sino del rumbo que pueda ser dado a su enseñanza cuya prioridad es no descuidar la dimensión ético-humanística de la medicina científica, humanizándola siempre más.

Si nos fijamos en el presente, pueden tomarse como referencia algunos de los métodos anticonceptivos considerados por muchos una amenaza a la vida o un crimen. $\mathrm{Si}$, a ejemplo de Foucault, se retrocede hasta el siglo XVIII, hay que enseñar que la ciencia ha sido utilizada de forma ambivalente; ha servido incluso para extinguir a muchos seres humanos. Desde hace décadas se sabe del uso criminal que se ha hecho del avance científico logrado con Edward Jenner cuando, en aquel siglo, desarrolla la primera vacuna contra la viruela.

No hay duda acerca de la importancia de esta contribución científica a la medicina; sin embargo, en las últimas décadas, varios autores (Schatzmayr, 2001; Silva, 2001; Garrett, 1995; McNeill, 1976) 
han enseñado la utilización del virus de la viruela como arma biológica de efecto letal contra poblaciones indefensas. Entre tantos hechos inhumanos puede recordarse el caso de la derrota de los aztecas en Méjico y, también, en los años 60 del siglo pasado, una epidemia en Kuwait con $43 \%$ de casos fatales; las fuentes referidas sugieren que hubo manipulación genética del virus de la viruela.

Estos hechos enseñan el reto que es para la ética o para la bioética el avance de la ciencia y la tecnología médicas. Hay que superar este divorcio de siglos entre ciencias humanas y ciencias biomédicas porque implica una amenaza a la humanidad. Si a la filosofía cabe vigilar los graves desafíos éticos derivados de la ciencia y la tecnología, esto es sólo una variante de la advertencia de Foucault cuando dice que desde Kant la filosofía ha tenido por función "impedir que la razón exceda los límites de lo que viene dado por la experiencia", es decir, la filosofía debe "vigilar los poderes excesivos de la racionalidad política" (Foucault, 2001b, p. 1043).

En consecuencia de todos estos desafíos, hay que decir que ninguna práctica tecnológica o científica debe desarrollarse aisladamente, al margen de una preocupación ética; cuanto más técnica o científica es una carrera, mayor es el desafío ético derivado de su desarrollo. Hay que superar el divorcio que se inició en la modernidad entre conocimiento científico y saber ético-humanista. Por fin, diseñada la problematización, las cuestiones que siguen tienen el objetivo de lograr una mayor precisión, incluso porque permiten enseñar el desarrollo dado a esta investigación:

- ¿Puede el filósofo aportar algo de nuevo y relevante a la medicina, un área muy impregnada de un creciente tecnicismo pragmatista? La obra de Foucault basta como referencia a esta cuestión;

- ¿Es válido considerar el testimonio ético de los médicos de la Antigüedad como recado y reto a los médicos contemporáneos? La investigación llevada a cabo es un intento de contestar a esta cuestión;

- La crítica de Foucault al humanismo moderno parece contradecir la afirmación que hago de una medicina humanista como herencia foucaultiana, por ello ¿cómo interpretarla huyendo de una posible paradoja? Esta cuestión es desarrollada de paso en mi investigación. En los escritos de la década de 60 y en otros más recientes (Foucault, 2001b, p. 1485), Foucault es muy crítico con relación a los llamados humanistas. Aunque considerado un antihumanista, él nos ha dejado como herencia el retrato de una medicina antigua absolutamente ético-humanística. Cuando insisto con este término, me refiero a una concepción que tiene el hombre como preocupación primera, tomado en su unidad y totalidad psicosomática; 
${ }^{3}$ Foucault desarrolla su pensamiento sobre la medicina social en conferencias impartidas en la Universidade do Rio de Janeiro en 1974. Estas conferencias fueron publicadas por segunda vez en DE I y tienen como título ‘Crise de la médecine ou crise de l'antimédecine' (p. 4058); 'La naissance de la médecine sociale' (p. 207-28);

'L'incorporation de l'hôpital dans la technologie moderne' (p. 508-22).

Posteriormente, en un artículo sobre 'La politique de la santé au XVIII siècle' (p. 725-42), Foucault añade más un poco al enfoque social de la medicina moderna.
- El título de esta investigación deja muy claro que en su genealogía, más que ética, Foucault retrata la dimensión humanística de la medicina griega y grecorromana. Con este término, que tiene mayor amplitud, se incluyen distintas expresiones de lo humanístico, además de lo ético y que fueron objeto de preocupación foucaultiana. Este autor dio prioridad a lo social de la medicina cuando analizó la medicina social como una invención del capitalismo ${ }^{3}$ en sus conferencias impartidas en Brasil. Él dio prioridad a lo ético de la medicina cuando, en su análisis de la relación del individuo con uno mismo y basado en el pensamiento médico de la Antigüedad, él enseña que la medicina antigua fue esencialmente ética (Foucault, 1984a, p. $129-83 ; 1984$ b, p. 135-93). A la postre, en todo su recorrido, desde la década de 50, este autor no descuidó la dimensión psicosomática del individuo al desarrollar sus críticas, aunque no sistematizándolas, a la psiquiatría y al psicoanálisis (Foucault, 1961; 1963). Para Foucault, la práctica psiquiátrica o psicoanalítica implica una relación jerárquica entre médico o psicoanalista y paciente, por ello él considera estas prácticas, médicas o paramédicas, como prácticas de control que impiden la subjetivación del individuo.

- Hoy los medios de comunicación divulgan siempre las consecuencias nefastas del avance de la ciencia y tecnología médicas; ¿puede la medicina científica, aisladamente, sin el compromiso ético-humanista de sus médicos, proporcionar a los enfermos, sobre todo al enfermo terminal, apoyo moral, calor afectivo y una muerte con dignidad, quitándole los sentimientos de soledad y abandono? Aunque muy lejos en el tiempo, la ética médica de los antiguos parece contestar diferentemente a las cuestiones puestas por la tecnología médica de hoy. Al lado de los enfermos, la solidariedad de Areteo parece desafiar a la frialdad o a la indiferencia de los médicos de la actualidad hacia los enfermos terminales ingresados en los hospitales: "cuando ya no cabe ningún tipo de ayuda, al médico aún le resta la posibilidad de sentir el dolor humano delante de su paciente incurable. Éste es el triste destino del médico" (Lyons y Petrucelli, 1997, p. 223).

- Otra cuestión muy actual es la expansión de una medicina como negocio que se extiende cada vez más como expresión de un capitalismo deshumano y salvaje. Si a Foucault no le ha interesado esta cuestión, ella es muy actual y tiene el reproche de Plinio en el pasado romano; de forma muy polémica, este escritor latino hace severas críticas a los médicos griegos acusándolos de un trabajo mercenario y poco ético cuyo resultado es acumular rentas y herencias exorbitantes. Como vemos, las 
fuentes indicadas por Foucault y otras lecturas complementarias a esta investigación continúan vigentes, aunque hacen poco caso de ellas los historiadores contemporáneos de la medicina.

- A partir del parangón establecido por Foucault entre moral pagana y moral cristiana, ¿valen sus inferencias a priori sobre una no subjetivación del individuo en la moral cristiana, o hay en ellas una inadecuación y una interpretación de matiz fundamentalista? Aunque traspase el objetivo de esta investigación, a esta cuestión muy poco profundizada y no suficientemente desarrollada por el filósofo, ensayo yo algunas sugerencias, pero de forma provisional y a título de provocación en la perspectiva de una posterior investigación, más larga y profundizada.

Como digo anteriormente, hay que superar el divorcio establecido entre el conocimiento médico-científico y el saber ético-humanista; hay que acercar las facultades de medicina y de filosofía mediante un trabajo compartido. Las fuentes utilizadas por Foucault muestran médicos cuya práctica es prioritariamente ética y filósofos cuyo discurso tiene como preocupación el ejercicio de la medi-cina. A partir del retrato dejado por el pensador francés ¿no cabría a la filosofía ponerse al servicio de la dignidad del hombre, comprometiéndose en contra de una práctica médica cada vez más deshumana y mercenaria? ¿Igualmente, no cabría a los médicos y enfermeros de hoy la preocupación ético-humanística identificada en los médicos del pasado? En la Antigüedad esto fue preocupación de médicos y filósofos, a ejemplo de Hipócrates y Platón, Celso y Plinio, Sorano y Plutarco.

En esta investigación, algunas de estas cuestiones fueron desarrolladas de forma no muy larga porque, aunque explicitadas, traspasan los objetivos aquí pretendidos, a ejemplo de la cuestión relacionada con la ética cristiana. Esta temática aparece muy frecuentemente en los últimos escritos de Foucault y me parece oportuna porque ella es constitutiva de su planteamiento. No hay duda de la influencia del cristianismo cuando la cuestión puesta tiene carácter moral.

A pesar de formal y académicamente concluida, hay que decir que esta investigación no puede agotar las cuestiones que en ella son objeto de cierto desarrollo. De hecho, pensar otra vez, aunque sea sobre las mismas cuestiones y a partir de los mismos escritos, es pensar diferente. Otra investigación a partir de los mismos problemas tendría otros desarrollos y otras conclusiones, aunque hechas por el propio Foucault. Él propio lo dijo, ya lo vimos, cuando afirma que la escritura de un nuevo libro transforma lo que pensaba en el libro antes escrito. Él tiene razón, pensar otra vez es pensar diferente; esto es propio de un filóso fo y nadie mejor que Foucault lo ha hecho en todos sus escritos. 


\section{Conclusiones}

Considerando que el objetivo de mi investigación es distinto del objetivo de Foucault al escribir su Historia de la sexualidad, las conclusiones de este trabajo tienen enfoque doble, por ello hay que evidenciar dos distintas formas de conclusiones. En primer lugar, hay aquéllas derivadas del texto foucaultiano y que tienen que ver con la ética; ellas traspasan pero se acercan de las que fueron explicitadas por él en el final de L'usage des plaisirs y de Le souci de soi. Estas conclusiones todavía son distintas porque resultan de otra investigación; no se trata de inferencias del filósofo, sino de inferencias propias de esta investigación. En segundo lugar, considerando que mi objetivo de investigación no es la elaboración de una genealogía de la ética, sino identificar la última aportación de Foucault a la historia de la medicina, hay que dilucidar esas conclusiones que, de hecho, indican la agregación de nuevos conocimientos y la aplicación de la filosofía a la historia de la medicina.

Seguidamente, esos dos enfoques de conclusiones aparecen de forma acoplada o distinta, aunque tienen un origen único: los escritos de Foucault y sus fuentes añadidas de otras complementarias y por mí utilizadas. Como vemos, es posible presentar unas cuantas conclusiones al final de este emprendimiento teórico-metodológico que, de hecho, significan una aportación de nuevos conocimientos a la dimensión deontológica de la ética filosófica y, también, a la dimensión ontológica de la ética médica, pues se trata de un análisis que, además de histórico, es filosófico. Helas aquí:

- Según Foucault, los griegos, alrededor de tres de los más importantes espacios del arte de la existencia, la dietética, la económica y la erótica, "desarrollaron artes de vivir, de comportarse y de usar los placeres según principios exigentes y austeros" (1984a, p. 321); en esta investigación considero que la medicina se constituye también en un espacio ético del arte de la existencia, considerando que la ética es prioridad absoluta en la relación que se establece entre médico y enfermo.

- En este análisis se destacan como parámetros de la moral griega la mesura, la armonía con la naturaleza y una severa austeridad con uno mismo. En los espacios del arte de la existencia, antes referidos, los filósofos y médicos griegos y grecorromanos fueron muy rigurosos en la aplicación de estos parámetros; hasta los autores latinos de esta época dan testimonio de la vigencia de esos parámetros, a ejemplo de Celso y otros escritores no referidos por Foucault como Plinio el Viejo, Marcial y, posteriormente, Celio Aureliano.

- Ética es el análisis foucaultiano diseñado en sus últimos escritos; ética es también la medicina griega o grecorromana 
presentada por este autor, sobre todo en L'usage des plaisirs y Le souci de soi. Si Foucault no lo ha formulado en la 'Conclusión' de uno y otro libro, es porque su blanco no era la medicina, sino la elaboración de una genealogía de la ética sexual moderna.

- Hay que explicitar que la medicina antigua fue una práctica esencialmente ética. Por otro lado, hay que decir que lo ético no agota lo humanístico ni éste se reduce a lo ético; lo humanístico tiene una mayor amplitud. Más que ética, esa medicina fue humanística, aunque sea ética la preocupación del filósofo cuando analiza el pensamiento de los médicos de la Antigüedad. La psicoterapia antigua y los principios del método hipocrático, analizados en esta investigación, presentan una preocupación que traspasa lo terapéutico y lo ético; no se trata de un cuidado con la enfermedad sino con el enfermo, considerándolo en su totalidad psicosomática. También Celso traspasa lo ético de la medicina cuando, preocupado con lo humano del paciente y frente a su miedo, recomienda al médico tranquilizarlo con palabras apropiadas antes de proceder a su exploración.

- De toda esta lectura de los escritos foucaultianos, de sus fuentes y de otras lecturas complementarias puede concluirse que en el pensamiento ético de filósofos y médicos de la Antigüedad griega se encuentran la genealogía de nuestros valores y principios morales, la cuna de nuestra ética sexual occidental y el origen de nuestra forma moral de pensar y sentir, de creer y ser.

- Hay que ser más específico y añadir que la ética sexual contemporánea del Occidente tiene su origen en el pasado griego y grecorromano, incluso muchos de los prejuicios y tabúes que persisten en nuestra sociedad moderna y que tienen el peso de su contexto socio-cultural y moral-religioso.

- Vale dilucidar que la ética médica inferida de este análisis tiene como trasfondo una supuesta Historia de la sexualidad. Como vemos, desde su cuna, la medicina antigua camina en pareja con la moral sexual; esto es muy evidente en el Juramento de Hipócrates y, también, en recomendaciones médicas que tratan de la relación entre salud y práctica del sexo, hechas por Areteo, Sorano y, sobre todo, Rufo de Éfeso.

- Como lo ético, también la dimensión social de la medicina es humanística; ella tiene como preocupación valores y necesidades humanas; en fin, la medicina social se preocupa con el hombre, como cuerpo vivo, considerado en su unidad psicosomática y dentro de un cuerpo social. Si el hombre es su cuerpo vivo, además de un cuerpo, él tiene una familia, una casa, una patria, que son posesiones suyas y hacen parte de su entorno y de su realización. La medicina antigua fue humanística porque los médicos hipocráticos y grecorromanos han priorizado estas cuestiones. 
${ }^{4}$ En DE II, Foucault desarrolla, respectivamente, la temática de la ética cristiana en dos artículos y dos conferencias que tienen como título: 'Le combat de la chasteté', 1982,

(p. 1114-27) y 'L'écriture de soi', 1983, (p. 1234-49); 'Sexualité et solitude' 1981 (p. 987-97) y

'Les technique de soi', 1982 (p. 1602-32).
- El enfoque político del trabajo médico es también expresión de una dimensión humanística de la medicina, por ello la medicina social y la salud pública, como extensión de la práctica médica a la ciudad, es un trabajo político y humanístico. De esta forma, como ser naturalmente social, la realización del hombre se cumple mediante una tarea que es política; su plena realización se hace en sociedad, por ello lo político como lo social en medicina son expresiones de su dimensión humanística.

- Del análisis de los últimos escritos foucaultianos y de sus fuentes también se llega a la conclusión que la ética de los antiguos tiene que ver con la práctica de la sexualidad; no fue el cristianismo, sino que fueron los filósofos y médicos de la Antigüedad pagana los primeros protagonistas de los cinco principios morales de nuestra ética occidental moderna. Tomados como punto de partida del análisis foucaultiano, estos principios pueden formularse de la forma que se sigue:

- una concepción negativa del acto sexual;

- la exigencia de la monogamia en la relación entre marido y mujer;

- la procreación como finalidad exclusiva del acto sexual;

- la descalificación de las relaciones homosexuales;

- la abstinencia sexual, la castidad y la virginidad como valores morales muy elevados.

- Desarrollada en los últimos escritos platónicos y objeto del último escrito de Foucault, la erótica filosófica es un discurso que atribuye a la abstención del sexo el verdadero acceso a la sabiduría y a la verdad; así siendo, esta erótica puede ser considerada también un espacio ético del arte de la existencia y un artificio filosófico que respalda y parece una antelación de la reflexión teológica de los Padres de la Iglesia, desde Clemente de Alejandría y San Agustín hasta final de la Patrística y los pensadores cristianos de la Edad Media.

- Vemos que en los dos últimos libros de Foucault hay muchas referencias a la ética cristiana. Sin embargo, se trata de referencias dispersas, desprovistas de sistematización y apenas apoyadas en fuentes explícitas. Éste no es el caso cuando este autor trata de la ética cristiana en sus pequeños escritos, constituidos de dos artículos y dos conferencias. ${ }^{4}$ En éstos, él se apoya en la Patrística griega y latina, pero Casiano, uno de los fundadores del monaquismo occidental, y San Agustín son las fuentes cristianas más referidas por el filósofo.

- De hecho, Foucault ha utilizado como fuentes de sus afirmaciones sobre la ética cristiana destacados e influyentes pensadores de la antigua tradición cristiana. No obstante, estas 
fuentes no son representativas de todo pensamiento cristiano, como no sería portavoz del cristianismo hoy un monje solo o los legítimos representantes del Vaticano. Sabemos que la ética de teólogos cristianos como Bernhard Häring, o incluso Schillebeeckx, Hans Küng, Torres Queiruga o Wolfhart Pannenberg, no es la ética del Vaticano, aunque todas sean cristianas. Con estas observaciones puede considerarse muy discutible la apreciación foucaultiana sobre la ética cristiana, hasta porque puede ser identificado cierto fundamentalismo en estas fuentes referidas por el filósofo.

- Los autores analizados indican que la recomendación de abstenerse de la actividad sexual no es un valor y una práctica exclusivos del cristianismo. A partir de la sospecha relativa a la practica del sexo, también los médicos griegos, a ejemplo de Sorano y Rufo de Éfeso, consideraron más saludable y una opción de vida superior al estado matrimonial la abstención de la actividad sexual; lo mismo que ha hecho San Pablo, por razones distintas, algunas décadas antes de aquéllos y San Agustín, tres siglos después.

- A Foucault cupo preocuparse con el hombre de forma holística. Sólo tomado en su unidad psicosomática el hombre puede ser considerado sujeto y, según él, es "el sujeto lo que constituye el tema general de sus investigaciones" (Foucault, 2001b, p. 1042). Por ello sus críticas a la psiquiatría y al psicoanálisis pueden ser atribuidas a esta su concepción de hombre como sujeto de sus propias acciones, considerando que para el filósofo, en estas prácticas médicas o paramédicas, el paciente no es sujeto sino objeto de un saber médico o psicoanalítico.

- La investigación llevada a cabo nos hace considerar que todo recorrido filosófico de ese autor y su teoría ética se convierten en referencia indispensable si se quiere rescatar la dimensión humanística de la medicina antigua como una referencia para la medicina contemporánea.

- En suma hay que concluir que Foucault ha dejado una teoría que permite reflexionar la dimensión humanística de la medicina en sus distintas expresiones. Él mismo lo ha hecho cuando analizó la medicina social como una invención del capitalismo; lo hace también cuando enseña que la medicina griega y grecorromana es una medicina esencialmente ética; él lo hace siempre, desde sus primeros escritos, cuando empieza a desarrollar sus críticas acerca de la psiquiatría y del psicoanálisis. El hilo conductor de su pensamiento, la radicalidad y criticidad propias de su desarrollo manifiestan que siempre le ha interesado el hombre como sujeto moral de sus acciones y el sujeto como tema general de sus investigaciones. 
Al final de estas conclusiones hay que llamar la atención para el carácter filosófico del análisis de Foucault y de esta investigación. Vimos que el análisis foucaultiano es filosófico en la medida en que su quehacer permite a su autor pensar de otro modo; también es filosófico su análisis y este trabajo porque, además del rigor y radicalidad en su método, su discurso porque cambia siempre tiene carácter provisional. Pensar filosóficamente es pensar de otro modo; la dinámica y los cambios propios del acto de pensar implican la provisionalidad del pensamiento filosófico. Luego, utilizar la filosofía para analizar la práctica médica es un intento de cambiarla porque pensar la medicina filosóficamente es pensarla diferente; por ello, cambiar la práctica médica puede ser una consecuencia de pensarla filosóficamente.

\section{REFERENCIAS BIBLIOGRÁFICAS}

Agostín, San

1984

Areteo de Capadocia 1998

Barros, Jac 2002

Casiano, Juan 1998

Celso, Cornélio 1966

Clemente de Alejandría 1998

Foucault, Michel 2003

Foucault, Michel 2001a

Foucault, Michel 2001b

Foucault, Michel 1996

Foucault, Michel 1984a

Foucault, Michel 1984b

Foucault, Michel 1984

Foucault, Michel 1984
De nuptiis et concupiscentia.

In: Obras completas, v. XXXV. Madrid: BAC.

Obra médica.

Miguel E. Pérez Molina (ed.) Madrid: Akal.

Pensando o processo saúde doença: a que responde o modelo biomédico? Revista Saúde e Sociedade, v. 11, n. 1, p. 67-84.

Colaciones.

2. ed. Madrid: Ed. RIALP.

De medicina.

Trad., prólogo y notas de Agustín Blánquez. Barcelona: Ed. Iberia.

El pedagogo.

Introd. por Ángel Castiñeira Fernández, trad. y notas por Joan Sariol

Díaz. Madrid: Gredos. [1. ed., 1988; reimpresión, 1998]

Le pouvoir psychiatrique.

Cours au Collège du France (1973-1974). Paris: Seuil/Gallimard.

Dits et écrits I, 1954-1975.

Paris: Gallimard.

Dits et écrits II, 1976-1988.

Paris: Gallimard.

Tecnologías del yo y otros textos afines.

Trad. de Mercedes Allendesalazar. Barcelona: Paidós.

Histoire de la sexualité.

2. L'usage des plaisirs. Paris, Gallimard.

Histoire de la sexualité.

3. Le souci de soi. Paris: Gallimard.

Le retour de la morale.

In: DE II, p. 1515-26.

À propos de la généalogie de l'éthique: un aperçu du travail en cours. In: DE II, p. $1202-30$ y p. $1428-50$. 


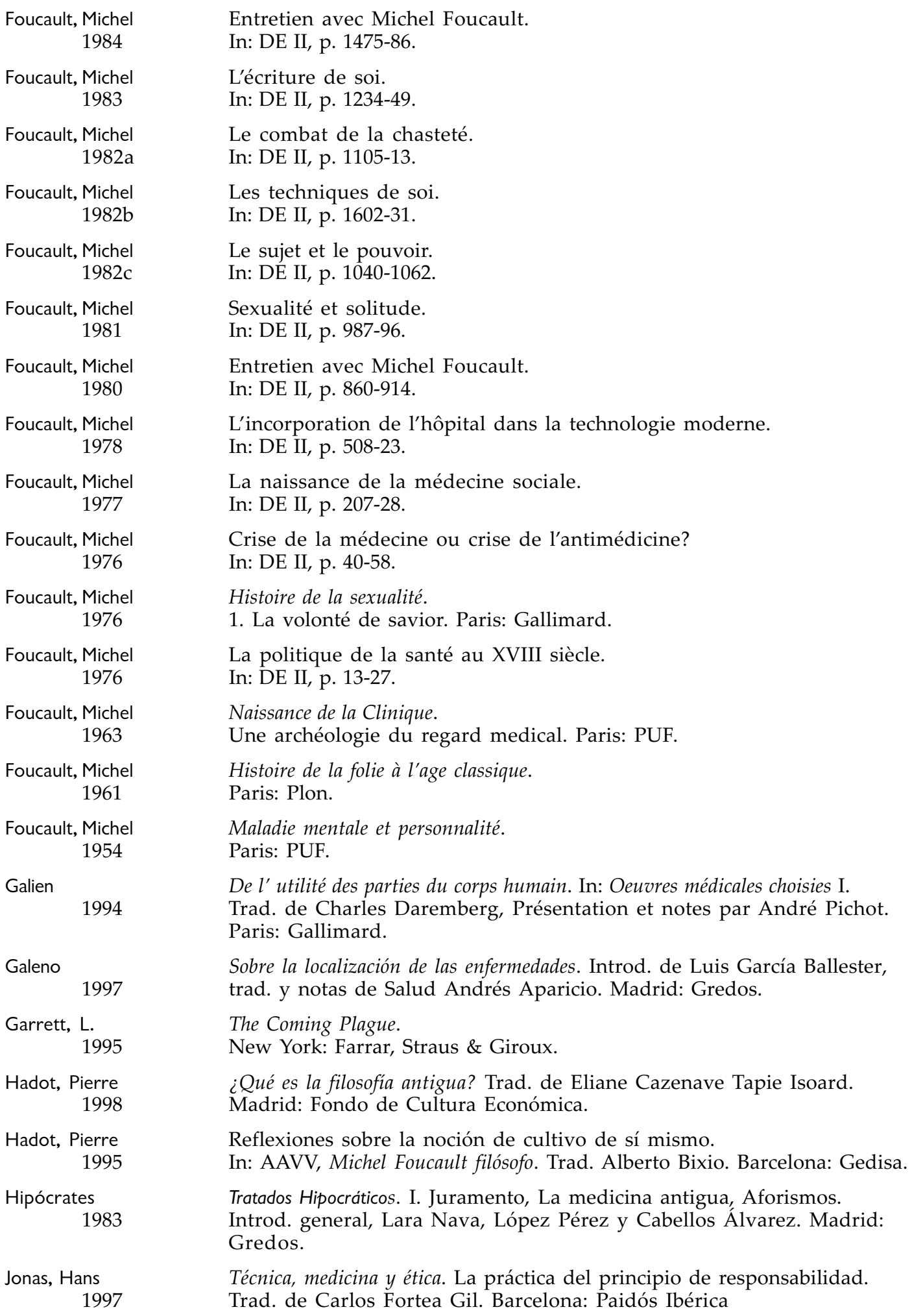

Entretien avec Michel Foucault. In: DE II, p. 1475-86.

L'écriture de soi. In: DE II, p. 1234-49.

Le combat de la chasteté. In: DE II, p. 1105-13.

Les techniques de soi. In: DE II, p. 1602-31.

Le sujet et le pouvoir. In: DE II, p. 1040-1062.

Sexualité et solitude. In: DE II, p. 987-96.

Entretien avec Michel Foucault. In: DE II, p. 860-914.

L'incorporation de l'hôpital dans la technologie moderne. In: DE II, p. 508-23.

La naissance de la médecine sociale. In: DE II, p. 207-28.

Crise de la médecine ou crise de l'antimédicine? In: DE II, p. 40-58.

Histoire de la sexualité.

1. La volonté de savior. Paris: Gallimard.

La politique de la santé au XVIII siècle.

In: DE II, p. 13-27.

Naissance de la Clinique.

Une archéologie du regard medical. Paris: PUF.

Histoire de la folie à l'age classique.

Paris: Plon.

Maladie mentale et personnalité.

Paris: PUF.

De l' utilité des parties du corps humain. In: Oeuvres médicales choisies I.

Trad. de Charles Daremberg, Présentation et notes par André Pichot. Paris: Gallimard.

Sobre la localización de las enfermedades. Introd. de Luis García Ballester, trad. y notas de Salud Andrés Aparicio. Madrid: Gredos.

The Coming Plague.

New York: Farrar, Straus \& Giroux.

¿Qué es la filosofía antigua? Trad. de Eliane Cazenave Tapie Isoard. Madrid: Fondo de Cultura Económica.

Reflexiones sobre la noción de cultivo de sí mismo. In: AAVV, Michel Foucault filósofo. Trad. Alberto Bixio. Barcelona: Gedisa.

Tratados Hipocráticos. I. Juramento, La medicina antigua, Aforismos. Introd. general, Lara Nava, López Pérez y Cabellos Álvarez. Madrid: Gredos.

Técnica, medicina y ética. La práctica del principio de responsabilidad. Trad. de Carlos Fortea Gil. Barcelona: Paidós Ibérica 
Lyons, Albert;

Petrucelli, Joseph 1997

Marcial 1997

McNeill, W. $\mathrm{H}$. 1976

Platon 1997

Plinio el Viejo 2003

Plutarco 1986

Rufus D’Éphèse 1879

Saviani, Dermeval 1980

Schatzmayr, Herman 2001

Silva, Luís Jacinto 2001

Soranos D’ Éphèse 2003
História da Medicina.

Trad. de Nelson Gomes de Oliveira. São Paulo: Manole.

Epigramas II.

Trad. y notas de Juan Fernández Valverde y Antonio Ramírez de Verger. Madrid: Gredos.

Plagues and People.

New York: Doubleday.

Fedón, Banquete, Fedro. In: Diálogos III. Trad. e introd. por García Gual, Martines Hernández y Lledó Iñigo. Madrid: Gredos. [1. ed., 1986; reimpresión, 1997]

Historia natural. Libros XXIX. Trad. y notas de Barrio Sanz, García Arribas, Ana Moure Casas et al. Madrid: Gredos.

Coniugalia preacepta y De tuenda sanitate. In: Obras Morales y de Costumbres (Moralia) II. Introd. y trad. de Concepción Morales Otal y José García López. Madrid: Gredos.

Fragments, conforme AETIUS. Oeuvres, texto y trad. francesa por Charles Daremberg y Etiene Ruelle. Paris: s.n.

Educação: do senso comum à consciência filosófica. São Paulo: Cortez.

A varíola, uma antiga inimiga.

Cad. Saúde Pública, v. 17, n. 6, p. 1525-30, nov.-dez.

Guerra biológica, bioterrorismo e saúde pública. Cad. Saúde Pública, v. 17, n. 6, p. 1519-23.

Maladies des femmes. Trad. et commentaires de Paul Burguiére, Danielle Gourervitch et Yves Malinas. Paris: Les Belles Lettres.

Recebido para publicação em abril de 2004.

Arovado para publicação em agosto de 2005. 